\title{
The Relation of Pre and Postnatal Depression and Anxiety with Exclusive Breastfeeding
}

\author{
Farangis Sharifi ${ }^{1}$, Soheila Nouraei ${ }^{2}$, Ehsan Shahverdi ${ }^{3,4}$
}

\author{
${ }^{1}$ Department of Midwifery, Kazerun Branch, Islamic Azad University, Kazerun, Iran \\ ${ }^{2}$ Department of Midwifery, Shahid Beheshti University of Medical Sciences, Tehran, Iran \\ ${ }^{3}$ Student Research Committee, Baqiyatallah University of Medical Sciences, Tehran, Iran \\ ${ }^{4}$ Blood Transfusion Research Center, High Institute for Research and Education in Transfusion Medicine, Tehran, \\ Iran
}

\section{Type of article: Original}

\begin{abstract}
Introduction: Studies on the relationship between prenatal psychosocial risk factors and breastfeeding are disjointed. Maternal health status has a great influence on breastfeeding, growth, and general health of the neonates. The aim of this study was to ascertain the relation between maternal mental health and breastfeeding status of mothers in Kazerun (Fars province, Iran).

Methods: This cross-sectional study was conducted on a total of 92 pregnant women recruited from clinics in Kazerun in 2015. Participants were divided into two groups subject to exclusive breastfeeding. Spielberger Anxiety Inventory, Beck Depression Inventory and Edinburgh Postnatal Depression Scale (EPDS) were used for data collection. Data analysis was performed by the SPSS version 16 using descriptive statistics, Chi-square, and Fisher's exact test.

Results: The average of state anxiety score according to Spielberger Anxiety Inventory was $1.97 \pm 0.51$ in the exclusive breastfeeding group versus $1.77 \pm 0.66$ in the non- exclusive breastfeeding group $(p=0.229)$. The mean trait anxiety score according to Spielberger Anxiety Inventory was $1.98 \pm 0.44$ in the exclusive breastfeeding group versus $2.22 \pm 0.44$ in the non- exclusive breastfeeding group ( $\mathrm{p}=0.132)$. An average of Beck Depression Inventory score was $1.35 \pm 0.84$ totally $(1.33 \pm 0.81$ in the exclusive breastfeeding group vs. $1.33 \pm 1.00, \mathrm{P}=0.584)$. An average of EPDS score was $1.65 \pm 1.11,1.64 \pm 1.11$, and $1.44 \pm 0.88$ in total, in the exclusive breastfeeding and non-exclusive breastfeeding groups, respectively $(\mathrm{p}=0.604)$.

Conclusions: Screening anxiety and depression before and during pregnancy appeared to be necessary.

Keywords: Breast feeding, Anxiety, Depression, Iran
\end{abstract}

\section{Introduction}

It has been proven that exclusive breastfeeding, which is confirmed to be the best source of nutriment for the first six months of an infant's life, has a positive effect on both infant and mother's health (1-3). According to a number of studies, psychosocial agents are a better predictor to anticipate the duration of exclusive breastfeeding, compared with demographic factors (4). Pre-partum anxiety and depression, which can lead to postpartum anxiety and depression, have an effect on breastfeeding cessation. $(5,6)$. Based on a number of other studies, there is an inverse association between breastfeeding frequency and maternal anxiety level (7). Breastfeeding cessation is also a cause of intensification of anxiety and depression (5). Optimal outcome is reported from mothers with exclusive breastfeeding (8). According to studies in countries outside of Iran, only slightly more than half of mothers would continue to exclusively breastfeed their infants until four months of age (9). A number of factors can lead to early cessation of breastfeeding. A mother's assumption that there is insufficient milk, infant agitation and crying, advice from friends and family, or a doctor's prescribed medicine. A decision to breastfeed is influenced by a mother's confidence, her ability to be discreet, her body image, previous experience, her child's age acceptance of female role,

\section{Corresponding author:}

Farangis Sharifi, Department of Midwifery, Kazerun Branch, Islamic Azad University, Kazerun, Iran.

Tel: +98.7142230507, Email: f_sharifi44@yahoo.com

Received: February 20, 2016, Accepted: August 14, 2016, Published: November 2016

iThenticate screening: August 01, 2016, English editing: October 15, 2016, Quality control: November 10, 2016

(C) 2016 The Authors. This is an open access article under the terms of the Creative Commons Attribution-NonCommercialNoDerivs License, which permits use and distribution in any medium, provided the original work is properly cited, the use is non-commercial and no modifications or adaptations are made. 
culture and child health status influence (10). Some factors such as anxiety, stress, and depression play an important role in failure to breastfeed (11). In addition, in mothers with higher levels of depression and anxiety, possibility of breastfeeding cessation increases (12).

\section{Material and Methods}

\subsection{Research design and setting}

This cross-sectional study was conducted on a total of 92 pregnant females recruited from Kazerun Clinics in Kazerun (Fars province, Iran) in 2015. The Participants were selected by convenient sampling strategy.

\subsection{Inclusion and exclusion criteria}

We considered a gestational age of 38-39 weeks and established absence of anxiety and depression before pregnancy as inclusion criteria. Participants with established anxiety and depression were excluded.

\subsection{Measurement tool and data collection}

The participants completed the demographic questionnaire and Spielberger Anxiety Inventory, Beck Depression Inventory, and Edinburgh Postnatal Depression Scale (EPDS). Spielberger Anxiety Inventory included two parts: chronic or trait anxiety (a general propensity to be anxious) and temporary or state anxiety (a temporary state varying in intensity)(13). The Beck Depression Inventory is a 21 -question multiple-choice self-report inventory, one of the most widely used psychometric tests for measuring the severity of depression (14). The Edinburgh Postnatal Depression Scale (EPDS) is a 10-item questionnaire developed to identify various clinical depression symptoms, such as feeling of guilt, sleep disturbance, low energy, anhedonia, and suicidal ideation (15). Overall assessment is completed by total score determined by adding together the scores for each of the 10 items. Higher scores indicate more depressive symptoms.

\subsection{Questionnaire design}

Questionnaires were designed by researchers and validated by eight psychiatrist. The reliability of the questionnaires was also checked by 30 pregnant women with a one-week interval. We asked 15 patients to complete the questionnaires two times with a one week interval to evaluate the questionnaire's reliability. For instrument validation, we used the content validity ratio and relevance, clarity, and simplicity content validity index. Pretestposttest and Cronbach's alpha were used to approve the internal consistency of the questionnaire. The McNemar and Kappa tests were used to prove the reliability of each question. The items of questionnaire were scored for necessity, relevance, clarity, and simplicity by eight psychiatrists with 10 years' experience and the content validity ratio and R- content validity index (CVR R-CVI), C- content validity index (C-CVI) and scale CVI (S-CVI) were measured. Based on Lawshe's table, level of significance was considered 0.75. There were no items with CVR and CVI lower than 0.75 . The internal consistency was approved (overall $\alpha=0.788$. knowledge part $\alpha=0.755$, attitude part $\alpha=$ 0.769 , and practice part $\alpha=0.845$ ). There were no significant differences between first and second answers. $(\mathrm{P}>0.05)$. The Kappa index was not lower than 0.2 in any item.

\subsection{Ethical Considerations}

The study was approved by the Ethics Committee of Islamic Azad University, Kazerun Branch. Written consent was obtained from all participants.

\subsection{Statistical Analysis}

Data were analyzed by SPSS version 16 (SPSS Inc., Chicago, Illinois, USA) using descriptive statistics, Chi-square, and Fisher's exact test.

\section{Results}

Eventually, 92 females with the mean age of $27.51 \pm 5.06$ and average age of marriage as $21.60 \pm 5.89$ years underwent analysis. The average age of their husbands was $32.98 \pm 7.23$. Table 1 shows distribution of demographic data in participants. Table 2 shows abortion and pregnancy history, breastfeeding history, history of nursing knowledge, the first type of nutrition, number of pregnancies, and nutritional status. According to this table, there was no significant relationship between abortion, pregnancy, breastfeeding history, history of breastfeeding knowledge, the first type of nutrition, and number of pregnancies with nutritional status ( $>0.05)$. Table 3 shows the distribution of anxiety and depression scores. According to this table, an average of state anxiety score according to Spielberger Anxiety Inventory was $1.94 \pm 0.56$ in all subjects. This rate was $1.97 \pm 0.51$ in the exclusive breastfeeding group versus $1.77 \pm 0.66$ in the non- exclusive breastfeeding group. There was no significant difference between the 
two groups in terms of nutritional status of infants $(\mathrm{p}=0.229)$. The mean trait anxiety score according to Spielberger Anxiety Inventory was $2.01 \pm 0.48$ in all subjects. This rate was $1.98 \pm 0.44$ in the exclusive breastfeeding group versus $2.22 \pm 0.44$ in the non- exclusive breastfeeding group. There was no significant difference between the two groups in terms of nutritional status of infants $(\mathrm{p}=0.132)$. An average of Beck Depression Inventory score was $1.35 \pm 0.84$ totally $(1.33 \pm 0.81$ in the exclusive breastfeeding group vs. $1.33 \pm 1.00, \mathrm{p}=0.584)$. An average of EPDS score was $1.65 \pm 1.11,1.64 \pm 1.11$, and $1.44 \pm 0.88$ in total, in the exclusive breastfeeding group, and non-exclusive breastfeeding group, respectively. There was no significant difference between the groups $(\mathrm{p}=0.604)$.

Table 1. Demographic Data $(\mathrm{n}=92)$

\begin{tabular}{|c|c|c|c|c|c|}
\hline \multicolumn{2}{|l|}{ Variable } & $\begin{array}{l}\text { Exclusive } \\
\text { breastfeeding }\end{array}$ & $\begin{array}{l}\text { Combined } \\
\text { feeding }\end{array}$ & $\begin{array}{l}\text { Artificial } \\
\text { feeding }\end{array}$ & $\begin{array}{l}\mathrm{p}- \\
\text { value }\end{array}$ \\
\hline \multicolumn{2}{|l|}{ Age } & $27.36 \pm 4.73)$ & $29.77 \pm 6.77)$ & 22.00 & 0.229 \\
\hline \multirow[t]{2}{*}{ Living place } & City & $68(98.6)$ & $9(100)$ & $1(100)$ & \multirow[t]{2}{*}{0.873} \\
\hline & Village & $1(1.40)$ & $0(0.0)$ & $0(0.0)$ & \\
\hline \multirow[t]{4}{*}{ Housing } & Private & $34(49.3)$ & $6(66.7)$ & $1(100)$ & \multirow[t]{4}{*}{0.876} \\
\hline & Mortgage & $6(8.7)$ & $1(11.1)$ & $0(0.0)$ & \\
\hline & Rent & $21(30.4)$ & $2(22.2)$ & $0(0.0)$ & \\
\hline & With relatives & $8(11.6)$ & $0(0.0)$ & $0(0.0)$ & \\
\hline \multirow{5}{*}{$\begin{array}{l}\text { Educational } \\
\text { level }\end{array}$} & Illiterate & $0(0.0)$ & $0(0.0)$ & $1(100)$ & \multirow[t]{5}{*}{0.089} \\
\hline & Elementary school & $8(11.6)$ & $2(22.2)$ & $0(0.0)$ & \\
\hline & High school & $17(24.6)$ & $2(22.2)$ & $0(0.0)$ & \\
\hline & Diploma & $26(37.7)$ & $3(33.3)$ & $0(0.0)$ & \\
\hline & Academic & $18(26.1)$ & $2(22.2)$ & $0(0.0)$ & \\
\hline \multirow[t]{2}{*}{ Job } & Housewife & $68(98.6)$ & $9(100)$ & $0(0.0)$ & \multirow[t]{2}{*}{0.025} \\
\hline & Employed & $1(1.4)$ & $0(0.0)$ & $0(0.0)$ & \\
\hline \multirow[t]{4}{*}{ Husband job } & Unemployed & $1(1.4)$ & $0(0.0)$ & $0(0.0)$ & \multirow[t]{4}{*}{0.559} \\
\hline & Worker & $17(24.6)$ & $2(22.2)$ & $1(100)$ & \\
\hline & Employee & $9(13.0)$ & $2(22.2)$ & $0(0.0)$ & \\
\hline & Self-employment & $42(60.9)$ & $5(55.6)$ & $0(0.0)$ & \\
\hline \multirow[t]{3}{*}{ Earnings } & Low & $23(33.3)$ & $2(22.2)$ & $0(0.0)$ & \multirow[t]{3}{*}{0.783} \\
\hline & Average & $41(59.4)$ & $6(66.7)$ & $1(100)$ & \\
\hline & High & $5(7.2)$ & $1(11.1)$ & $0(0.0)$ & \\
\hline
\end{tabular}

Table 2. Previous pregnancies status history $(\mathrm{n}=92)$

\begin{tabular}{|c|c|c|}
\hline \multicolumn{2}{|c|}{ Variable } & $\mathrm{n}(\%)$ \\
\hline \multirow[t]{2}{*}{ History of abortion } & No & $79(85.9)$ \\
\hline & Yes & $13(14.2)$ \\
\hline \multirow[t]{2}{*}{ Current pregnancy status } & Wanted & $77(83.7)$ \\
\hline & Unwanted & $15(16.3)$ \\
\hline \multirow[t]{2}{*}{ Breastfeeding history } & Yes & $52(56.5)$ \\
\hline & No & $40(43.5)$ \\
\hline \multirow[t]{2}{*}{ Breastfeeding knowledge } & Yes & $66(71.7)$ \\
\hline & No & $24(26.1)$ \\
\hline \multirow[t]{2}{*}{ First type of nutrition } & Breast milk & $63(68.5)$ \\
\hline & Milk powder & $14(15.2)$ \\
\hline \multirow[t]{2}{*}{ First lactation } & 1 hour after Delivery & $52(56.5)$ \\
\hline & $>1$ hour after Delivery & $29(31.5)$ \\
\hline \multirow[t]{3}{*}{ Nutritional status } & Exclusive breastfeeding & $69(75.0)$ \\
\hline & Combined feeding & $9(9.8)$ \\
\hline & Artificial feeding & $1(1.1)$ \\
\hline \multirow[t]{5}{*}{ Number of pregnancies } & One & $47(51.1)$ \\
\hline & Two & $33(35.9)$ \\
\hline & Three & $7(7.6)$ \\
\hline & Four & $4(4.3)$ \\
\hline & Five & $1(1.1)$ \\
\hline
\end{tabular}


Table 3. Prenatal Anxiety (Spielberger Criteria), Depression, and Postpartum Anxiety by Exclusive Breastfeeding, Combined Feeding and Artificial Feeding

\begin{tabular}{|c|c|c|c|c|c|}
\hline \multicolumn{2}{|l|}{ Spielberger } & $\begin{array}{l}\text { Exclusive } \\
\text { breastfeeding }\end{array}$ & $\begin{array}{l}\text { Combined } \\
\text { feeding }\end{array}$ & $\begin{array}{l}\text { Artificial } \\
\text { feeding }\end{array}$ & $\begin{array}{l}\mathrm{p}- \\
\text { value }\end{array}$ \\
\hline \multicolumn{2}{|l|}{ Mild } & $10(14.7)$ & $3(33.3)$ & $1(100)$ & \multirow[t]{3}{*}{0.145} \\
\hline \multicolumn{2}{|c|}{ Relatively mild } & $50(73.5)$ & $5(55.6)$ & $0(0.0)$ & \\
\hline \multicolumn{2}{|c|}{ Relatively severe } & $8(11.8)$ & $1(11.1)$ & $0(0.0)$ & \\
\hline \multirow[t]{3}{*}{ Spielberger } & Mild & $7(10.3)$ & $0(0.0)$ & $0(0.0)$ & \multirow[t]{3}{*}{0.507} \\
\hline & Relatively mild & $55(80.9)$ & $7(77.8)$ & $1(100)$ & \\
\hline & Relatively severe & $6(8.8)$ & $2(22.2)$ & $0(0.0)$ & \\
\hline \multirow[t]{4}{*}{ Beck } & Normal & $55(79.7)$ & $8(88.9)$ & 1 & \multirow[t]{4}{*}{0.514} \\
\hline & Mild & $10(14.5)$ & $0(0.0)$ & $0(0.0)$ & \\
\hline & $\begin{array}{l}\text { Relatively } \\
\text { depressed }\end{array}$ & $3(4.3)$ & $1(11.1)$ & $0(0.0)$ & \\
\hline & Severe depressed & $1(1.4)$ & $0(0.0)$ & $0(0.0)$ & \\
\hline \multirow{4}{*}{ EPDS } & Normal & $48(70.6)$ & $7(77.8)$ & $0(0.0)$ & \multirow[t]{4}{*}{0.077} \\
\hline & Mild & $6(8.8)$ & $0(0.0)$ & $1(100)$ & \\
\hline & Moderate & $4(5.9)$ & $2(22.2)$ & $0(0.0)$ & \\
\hline & Severe & $10(14.7)$ & $0(0.0)$ & $0(0.0)$ & \\
\hline
\end{tabular}

EPDS $=$ Edinburgh Postnatal Depression Scale

\section{Discussion}

We found that state anxiety score was non-significantly higher in the exclusive breastfeeding group in comparison to females with combined feeding. Trait anxiety and Beck Depression score was lower in the exclusive breastfeeding group but EPDS score was higher. Akman et al. (16) showed an association between higher EPDS scores and breastfeeding cessation by four months after delivery. According to Groër et al. (17) study, breast- feeders had lower depression and anger and more positive life events reported, than formula-feeders. Tarayn et al. (6) concluded that prenatal depressive symptoms and high pregnancy-related anxiety were not associated with failure to initiate breastfeeding. This confirmed our result because according to our study, state anxiety score was non-significantly higher in the exclusive breastfeeding group. According to an Ushma study (18), depression and anxiety levels were not found to mediate the association between pregravid BMI and breastfeeding initiation. We did not evaluate the role of BMI in breastfeeding initiation but state anxiety level was not a risk factor for delay in breastfeeding initiation. Tabassum et al. (19) showed that women with high perceived stress in early pregnancy and high anxiety in early pregnancy and mid-pregnancy were less likely to intend to breastfeed. They also concluded that women with minor depression according to EPDS score were less likely to intend to breastfeed compared to women without depressive symptoms. In the recent study, EPDS score was higher in women with exclusive breastfeeding. Figueiredo et al. (20) demonstrated that depression scores at the third trimester, but not at 3 months postpartum, were the best predictors of exclusive breastfeeding duration. Our study confirmed these findings. Assarian et al. (9) linked breastfeeding status with susceptibility to depression. Furthermore, they concluded that there was a significant association between basic characteristics such as maternal occupational status or their respective education with breastfeeding. In our study, there was no significant difference between exclusive and non- exclusive breastfeeding groups in term of occupational status or educational levels. Iran is a large country in the Middle East and different ethnic groups live in different areas. Differences in living conditions in the various regions cause distinct prevalence rates of disorders such as stress and depression. This study was conducted in one of the small towns, so the results of the recent study are not generalizable to large populations and main cities.

\section{Conclusions}

We concluded that pre and postnatal depression and anxiety had lower incidence in females with exclusive breastfeeding. According to recent study, psychosocial risk factors before pregnancy are important predictors of breastfeeding. In a healthcare setting highly supportive of breastfeeding, women with prenatal depressive symptoms and anxiety were less likely to plan prenatally to breastfeed. According to some different results of our study and previous studies, regarding the importance of mental health issues and the importance of exclusive breastfeeding, it is recommended to evaluate breastfeeding in pregnancy trimesters and also in patients with psychological disorders as case control study. 


\section{Acknowledgments:}

We thank the personnel of Islamic Azad University, Kazerun Branch, Fars, Iran and Kazerun health network staff who helped us with sampling and procedures during the study.

\section{Conflict of Interest:}

There is no conflict of interest to be declared.

Authors' contributions:

All authors contributed to this project and article equally. All authors read and approved the final manuscript.

\section{References:}

1) Kramer MS, Kakuma R. The optimal duration of exclusive breastfeeding. Protecting Infants through Human Milk: Springer; 2004; 554: 63-77.

2) WHO. Exclusive breastfeeding for six months best for babies everywhere. Geneva: WHO. 2011.

3) Oddy W, De Klerk N, Sly P, Holt P. The effects of respiratory infections, atopy, and breastfeeding on childhood asthma. Eur Respir J. 2002; 19(5): 899-905. PMID: 12030731.

4) O'Brien M, Buikstra E, Hegney D. The influence of psychological factors on breastfeeding duration. J Adv Nurs. 2008; 63(4): 397-408. doi: 10.1111/j.1365-2648.2008.04722.x. PMID: 18727767.

5) Ystrom E. Breastfeeding cessation and symptoms of anxiety and depression: a longitudinal cohort study. BMC pregnancy and childbirth. 2012; 12(1): 36. doi: 10.1186/1471-2393-12-36.

6) Fairlie TG, Gillman MW, Rich-Edwards J. High pregnancy-related anxiety and prenatal depressive symptoms as predictors of intention to breastfeed and breastfeeding initiation. J Womens Health (Larchmt). 2009; 18(7): 945-53. doi: 10.1089/jwh.2008.0998. PMID: 19563244, PMCID: PMC2851128.

7) Çiftçi EK, Arikan D. The effect of training administered to working mothers on maternal anxiety levels and breastfeeding habits. J Clin Nurs. 2012; 21(15 - 16): 2170-8. doi: 10.1111/j.1365-2702.2011.03957.x. PMID: 22151299.

8) Zubaran C, Foresti K. The correlation between breastfeeding self-efficacy and maternal postpartum depression in southern Brazil. Sex Reprod Healthc. 2013; 4(1): 9-15. doi: 10.1016/j.srhc.2012.12.001. PMID: 23427927.

9) Assarian F, Moravveji A, Ghaffarian H, Eslamian R, Atoof F. The association of postpartum maternal mental health with breastfeeding status of mothers: a case-control study. Iran Red Crescent Med J. 2014; 16(3). doi: 10.5812/ircmj.14839. PMID: 24829776, PMCID: PMC4005438.

10) Wagner CL, Wagner MT, Ebeling M, Chatman KG, Cohen M, Hulsey TC. The role of personality and other factors in a mother's decision to initiate breastfeeding. J Hum Lact. 2006; 22(1): 16-26. doi: 10.1177/0890334405283624. PMID: 16467284.

11) Hurley KM, Black MM, Papas MA, Caufield LE. Maternal symptoms of stress, depression, and anxiety are related to nonresponsive feeding styles in a statewide sample of WIC participants. J Nutr. 2008; 138(4): 799-805. PMID: 18356338, PMCID: PMC3137941.

12) Taveras EM, Capra AM, Braveman PA, Jensvold NG, Escobar GJ, Lieu TA. Clinician support and psychosocial risk factors associated with breastfeeding discontinuation. Pediatrics. 2003; 112(1): 108-15. PMID: 12837875.

13) Spielberger CD. Test anxiety inventory: Wiley Online Library; 2010.

14) Beck AT, Steer RA, Brown GK. Beck depression inventory-II. San Antonio, TX. 1996: 78204-2498.

15) Cox JL, Holden JM, Sagovsky R. Detection of postnatal depression. Development of the 10-item Edinburgh Postnatal Depression Scale. The British journal of psychiatry. 1987; 150(6): 782-6.

16) Akman I, Kuscu MK, Yurdakul Z, Özdemir N, Solakoğlu M, Orhon L, et al. Breastfeeding duration and postpartum psychological adjustment: role of maternal attachment styles. J Paediatr Child Health. 2008; 44(6): 369-73. doi: 10.1111/j.1440-1754.2008.01336.x. PMID: 18476931.

17) Groër MW. Differences between exclusive breastfeeders, formula-feeders, and controls: a study of stress, mood, and endocrine variables. Biol Res Nurs. 2005; 7(2): 106-17. doi: 10.1177/1099800405280936. PMID: 16267372.

18) Mehta UJ, Siega-Riz AM, Herring AH, Adair LS, Bentley ME. Maternal obesity, psychological factors, and breastfeeding initiation. Breastfeed Med. 2011; 6(6): 369-76. doi: 10.1089/bfm.2010.0052. PMID: 21492019, PMCID: PMC3228590. 
19) Insaf TZ, Fortner RT, Pekow P, Dole N, Markenson G, Chasan-Taber L. Prenatal stress, anxiety, and depressive symptoms as predictors of intention to breastfeed among Hispanic women. J Womens Health (Larchmt). 2011; 20(8): 1183-92. doi: 10.1089/jwh.2010.2276. PMID: 21668379.

20) Figueiredo $B$, Canário $C$, Field $T$. Breastfeeding is negatively affected by prenatal depression and reduces postpartum depression. Psychol Med. 2013; 44(5): 927-36. doi: 10.1017/S0033291713001530. PMID: 23822932 . 